\title{
"It Felt Like a Little War": Reflections on Violence against Alternative Subcultures
}

\begin{abstract}
This article examines the forms and impact of violence against people identifying as members of alternative subcultures. It draws upon the findings from interviews and focus groups undertaken with over 60 participants from a range of alternative subcultural backgrounds, conducted as part of a broader two-year study of many different strands of targeted hostility. The article presents evidence to show that 'alternatives' are subjected to a wide range of violent and intimidatory behaviour, from 'everyday' abuse such as verbal insults through to more extreme acts of brutality. This can affect their physical and mental health, causing them to change the way they conduct their routine activities. However, the article suggests that some of this victimisation forms part of ongoing conflict with a group that participants describe as 'chavs', that has hitherto been unacknowledged. This 'little war' is characterised by mutual hostility and antipathy flavoured by class antagonism that can escalate into violent confrontation.
\end{abstract}

\section{Keywords}

Targeted hostility, victimisation, hate crime, identity, violence, harassment, alternative subcultures, 'chavs', class, goths

\section{Authors}

Jon Garland (University of Surrey), Neil Chakraborti (University of Leicester) and Stevie-Jade Hardy (University of Leicester)

\section{Corresponding Author}

Jon Garland

Department of Sociology

AD Building

University of Surrey 
Guildford

GU2 2XH

j.garland@surrey.ac.uk

\section{Introduction}

The decision taken by Greater Manchester Police (GMP) in April 2013 to record attacks upon members of alternative subcultures as hate crimes was a significant development in the way that criminal justice organisations categorise incidents of targeted violence. In addition to the five victim 'strands' that are accorded official recognition within United Kingdom hate crime policy (race/ethnicity, religion, disability, sexual orientation or gender identity), GMP stated that it would henceforth acknowledge a new, sixth strand of 'alternative subculture'. By doing this, the force hoped it would be able to develop a better understanding of this type of harassment and thereby improve the service it provides to victims (GMP, 2013).

This development marked GMP as the first UK police service to accord hate crime victim group status to members of alternative subcultures. It also underscored the influence of a pressure group, the Sophie Lancaster Foundation, which has been campaigning for this recognition since its inception in $2007^{1}$. However, GMP's decision not only posed a number of dilemmas for other police forces and criminal justice agencies regarding how they classify and monitor hate crime; it also (inadvertently) challenged the theoretical underpinnings of hate crime developed in the main by North American academics such as Perry (2001) that have been so influential in the evolution of scholarship in this field. Within these frameworks, hate crime is understood to be the harassment and intimidation of marginalised minority 'outgroups' by society's more dominant strata, with the purpose of reminding them of their subordinate place in the social hierarchy. Through its recognition of their common history of being the recipients of prejudiced hostility while campaigning for civic equality, the concept of 'hate crime' gives these minority communities a unifying cause around which they can rally. GMP's stance on hate crime challenges this notion by including a group - alternative subcultures (or 'alternatives') - that, by its predominantly middle class and white composition (Hodkinson, 2002; 2013), does not fit the typical profile of a group with a past characterised by discrimination and hate crime victimisation. Instead, GMP's initiative points towards recent developments in understandings of hate crime that are less concerned with these structural notions of dominance and subordination and are instead more focused upon the suggestion that acts of hate can be predicated upon how vulnerable the intended victim is in the eyes of the perpetrator (see 
Chakraborti and Garland, 2012), whatever background (minority or not) they have. It is the perpetrator's hostility and prejudice towards their target, and their perception of the vulnerability of that target, that play a crucial role in the process of enacting hate.

Therefore, the dual aspects of GMP's recognition of 'alternatives' as a hate crime victim group - the challenges it poses to practitioner and to scholarly understandings of hate crime victimisation made the authors' analysis of the targeted hostility suffered by alternative subcultures uncovered in the Leicester Hate Crime Project all the more timely from both a policy and conceptual perspective. The Leicester Hate Crime Project was a large-scale hate crime victimisation study conducted in the city of Leicester in the East Midlands of England and this article examines the evidence collated from one aspect of this research: a series of interviews undertaken with members of alternative subcultures. Following an outline of the project and its methodology, and a necessarily brief review of the existing literature, the article explores the extent, forms and impact of attacks upon 'alternatives'. The article does not seek to assess the nature of alternative subcultural communities themselves or to provide a definitive answer to the question of whether they should be considered a hate crime victim group or not (see Chakraborti and Garland (2015) for a discussion of these points). Instead, the focus of the article is upon their experiences of targeted hostility, its impact and how it is coped with and resisted. As shall become apparent, much of this abuse and violence is more complex than might appear at face value, and, while it reflects many of the elements of the more recent theoretical developments in hate crime scholarship, it also includes forms of class antagonism that add further layers to this complicated theoretical picture.

\section{Alternative Subcultures}

While there is no single definitive notion of what may constitute an 'alternative subculture' it is generally acknowledged within relevant literature that such subcultures are characterised by the adoption of strikingly different hairstyles, clothes, accessories, piercings and sometimes body art that are markedly apart from what is commonly viewed as 'high street' fashion and from the more 'everyday' appearances of other youth subcultures such as mod or casual (Brill, 2008; Goulding and Saren, 2009). Music is a central part of these scenes too, and similarly exists outside of the mainstream. It provides the soundtrack in shared spaces, such as 'alternative' nightclubs and gig venues, which offer relatively safe locations within which to congregate with other 'outsiders'.

As the definition adopted by Greater Manchester Police in 2013 acknowledges, while a list of such groups is difficult to compile absolutely, those considered to exist "under the "alternative" umbrella include Goths, Emos, Punks and Metallers' (GMP, 2013), and skaters are often regarded in this way 
too. Some of these subcultures, such as goth, involve the wearing of black clothing linked to a strong interest in the macabre, which makes them recognisably 'darker' and more sinister than other subcultural scenes (Goulding and Saren, 2009). Others, such as punk, can be spectacularly colourful and provocative. All are more complicated than may appear at first and have a number of different 'looks' within them: goth, for example, boasts a range of sartorial styles that go with certain subscenes, ranging from folk, electro and industrial goth to rock and metal (Brill, 2008). However, often what links many alternative subcultures is a strong sense of the shared experience of being 'different' and outside of the 'norm', meaning that the lines between different subcultures can become blurred. Indeed, participants (such as some goths and metallers) can often identify with aspects of each other's music, clothes and outlook, and will mix cordially at music venues and in clubs (Brill, 2008). This reflects the widely-held view within these subcultures that they are more tolerant and welcoming of difference, whether in appearance, lifestyle or sexual orientation (for example), than those they deem to be from 'mainstream' society.

\section{About the Leicester Hate Crime Project}

The interviews that inform this article were one aspect of a much larger piece of research, the Leicester Hate Crime Project, which was a two-year hate crime victimisation study funded by the Economic and Social Research Council that ran from 2012-14². The project was based in Leicester, a city with a population of around 330,000 situated in the East Midlands. It was chosen as the location for the study due to its multiculturalism and extraordinarily diverse population. The aims of the project were twofold: to develop an understanding of the victimisation process in cases where the victim feels they have been targeted because of their identity or perceived 'difference', and to assess victims' views of criminal justice agencies' responses to their incident(s). It was therefore a deliberately broad study of the nature, extent and impact of targeted hostility, and participants were not restricted to the five officially recognised hate crime victim groups mentioned above: anyone who felt that they had been targeted because of who they were, no matter what their background, was eligible to be included. Our sample of subcultural participants was therefore recruited through this process.

In order to understand these broader patterns of victimisation and the detail of people's experiences, a mixed-method approach was adopted. This included a victimisation survey conducted online and via hard-copy questionnaires that generated more than 1,100 responses, as well as indepth semi-structured interviews with nearly four hundred separate victims. In an effort to attract participants, the project was widely publicised in Leicester via local media outlets, community 
centres and gatekeepers. However, it was a more grassroots-based approach to participant engagement - which involved the research team spending prolonged periods of time developing contacts via face-to-face interactions with the public in places such as health and neighbourhood centres, international supermarkets, pubs and bars, cafes and restaurants, taxi ranks, shelters and support services for those with drug, alcohol or other issues - which facilitated relationships of trust and connections with thousands of people from 'hard to reach' groups, and which generated the vast majority of interviewees and questionnaire respondents. ${ }^{3}$

As the research team were keen to uncover the detail of the multiple facets of targeted victimisation we decided to conduct the 'alternative subculture' aspect of the wider project via the collection of 62 life stories obtained through interviews. ${ }^{4}$ These were most often conducted on an individual basis but occasionally in small groups, and typically lasted from 45 to 75 minutes. All of those participating defined themselves as 'alternative', with some adopting that as their sole subcultural descriptor while others saw themselves more specifically as goths, punks or metallers. Just under half were male (30, compared to 32 females), with ages ranging from late teens to mid-50s, and all were white British. All but two were in full-time employment, with occupations including teacher, administrator, waitress, care worker, youth worker, researcher, student, planning co-ordinator, personal assistant and bank clerk. They were recruited specifically for the 'alternative' strand of the wider project through the on-the-ground, grassroots approach utilised for the research more broadly. This was done initially via contacts made through participant observation of a metal music festival which attracted a largely nu-metal, goth and punk audience, and then via a word-of-mouth snowballing process that extended through the city's alternative subcultural networks. The only caveats for participation in the research were that potential interviewees had to define themselves as coming from an alternative subculture and, in line with the project's key aims, must have previously been victimised because of that identity characteristic. Informed consent was obtained from each participant and steps taken to minimise any harm or upset that talking about their victimisation might precipitate through the provision of the contact details of support services and the reassurance that they could withdraw from their interview at any point.

\section{The Targeting of Alternative Subcultures}

While the study of youth subcultures has been evolving over a number of decades (see, for example, Cohen, A., 1955; Becker, 1963) much of this work has focused upon the complexities and nuances of the subcultures themselves, the social backgrounds of those involved and the motivations behind their participation. Instructive though this body of work is, it has infrequently examined disorderly or 
criminal behaviour (see Cohen, S. 1972; Fowler, 2008), with Hebdige's (1979) analysis of the violence of skinheads being a rare example of a more sociological investigation of the types of targeted harassment relevant to this article. Hebdige briefly speaks of the 'scapegoating' of 'alien groups' (such as south Asian and gay communities) by the skinheads but does not expand further on the patterns and impact of this violence, and in any case focuses on the perpetration of violence by a subcultural group rather than them being the victims of it. Meanwhile, much of the influential work of the Centre for Contemporary Cultural Studies assesses inter-group conflict (such as Cohen, P., 1972). There is much less work on members of subcultures being targeted due to hostility towards their subcultural identity.

Of some relevance is Clarke's (1976) work on skinheads and whether societal hostility caused members to desist from belonging to such groups or to develop stronger bond with them, while Jefferson (1976) outlines how being on the receiving end of abuse and harassment increased feelings of shared subcultural identity among teddy boys (see also Gaines (1990), Thornton (1995) and Brown (2011) for analyses of media and social stigmatisation of subcultural groups). Notwithstanding this corpus of work, there is surprisingly little research evidence on the targeted victimisation suffered by subcultural members. Leblanc's (2008) ethnographic account of female punks in the United States and Canada does, though, reveal a pattern of abuse that her research participants were subjected to as they went about their daily lives. Those she observed were subjected to a 'vast amount' (ibid: 179) of verbal abuse from members of the public, as well as other forms of harassment such as being spat at, being denied service in shops or drinks establishments, being falsely accused of stealing, being avoided and being abused by the occupants of passing cars. Leblanc (2008: 169) additionally noted that 'interactions with the general public play such an important role in consolidating a subculture, establishing its boundaries and compelling its members' commitment'; a phenomenon also mentioned by Hodkinson in his study of goths (Hodkinson, 2002) and by some of the subcultural theorists mentioned above. However, neither Hodkinson nor Brill (2008, in her examination of the goth scene) offer significant detail on the kinds of harassment that goths suffer. Garland (2010) suggests that this type of hostility may be more frequent and widespread than commonly thought, and cites anecdotal evidence and a number of documented cases across the UK in which goths and 'alternatives' have been violently assaulted, abused, bullied and harassed. He suggests that these incidents in many ways resemble officially recognised hate crimes, in that they are often perpetrated by those who are strangers to the victim but have 'othered' them due to an extreme dislike or fear of their strikingly different appearance. He suggests that goths may be additionally vulnerable due to a perception that they are 'bookish', nonviolent and therefore an 'easy target' (Garland, 2010). Garland and Hodkinson (2014) argue that this 
harassment can impact upon the wider goth community who identify with the victimisation of others in their subculture. However, these latter studies of the goth and alternative scenes do not have a firm empirical basis and are, in the main, a theoretical assessment of the targeted victimisation of those subcultures, or are based upon media coverage and anecdotal evidence. The current study, centred as it is in original fieldwork, offers new insights into this phenomenon. It is to an analysis of its findings that this paper now turns.

\section{Nature and Extent of Victimisation}

All of our alternative subcultural interviewees had been regular victims of targeted hostility and 'everyday' harassment. Typical of the kind of insults recalled were 'freak', 'dirty mosher' or 'grunger', with 'greb' (a derivative of 'grebo', a slang term for metallers or bikers) an especially common term of abuse. Often these taunts would come from people passing by in cars or on foot, and were so frequent that many would simply become inured to them, as the following comments suggest:

The name calling came from people leaning out of cars and yelling, "You greb!". You just got used to that, you didn't really care about that. "You're a greb!"; well spotted! (Mike, 23).

People shouting or spitting or throwing bottles from cars or stuff like that ... happened all the time, it was nothing out of the ordinary at all (Louise, 24).

It was commonplace for us to either be spat on, have something thrown at us, or be called things (Paul, 32).

Interestingly, around two-thirds of our interviewees described the process of being verbally abused as 'random', emphasising the seemingly senseless nature of being insulted by those who were, more often than not, complete strangers. Others spoke of being intimidated by overhearing groups of youths shouting 'Let's go goth bashing!' as they left their local college. Around a third also mentioned that they were 'constantly' accused of being 'filthy' or 'dirty', and that they 'were nothing' or 'would never amount to anything', with their accusers apparently associating long hair or alternative dress with being unkempt and feckless. Some of our interviewees who had adopted a more androgynous style of dress had received homophobic abuse, with goth males being called 'poofs' for being effeminate in appearance, while females were abused as 'dykes' for adopting a more masculine style of clothing. 
Just over half of victims referred to being the recipients of hostile stares or gestures, or being avoided. Lucy (53) mentioned that, while in a pub in the city centre, two 'old ladies' had taken one look at her and her partner sitting at the table next to them and decided to move, 'presumably because we looked different and we were likely to misbehave'. Others described being jostled, threatened or spat at in the street, with some mentioning that a favourite 'tactic' was for someone to jump right in front of them as they were walking, causing them to stop dead in their tracks or risk bumping into their harasser; something that they feared might escalate the situation. This 'performance' was nearly always accompanied by derogatory comments.

More than two-thirds of our sample of 'alternatives' had experienced physical violence, with approximately one-in-five having suffered it on a regular basis. Experiences ranged from having drinks poured over clothes, milkshakes and juices thrown from cars and coins aimed in their direction, to being kicked and punched. Interviewees concurred that while males were generally more likely to be subject to physical assault than females, both sexes were known to have been victimised. These unprovoked assaults occurred most often in the street, in a park or on public transport, as described by one of our interviewees:

We were on the bus and heard this noise, and this egg exploded over one of the girls. They just started throwing eggs at us! We went downstairs, and they decided to follow us downstairs and try and push us about (Joe, 23).

Many victims described feeling bemused or astonished immediately after being victimised, as they struggled to comprehend why they had been targeted by strangers in what initially felt like a motiveless assault. They had simply been minding their own business when they had been subjected, out of the blue, to physical attack. These events were often accompanied by verbal abuse that indicated that the incident had been triggered by some form of animosity towards their subcultural appearance:

Once I was walking down to my mate's house in Braunstone ${ }^{5}$. There were three of them on bikes, just riding, sort of looking at me and everything, then one of them punches me in the face. I looked round and they were just bombing off, shouting stuff (Joe, 23). 
We were walking in opposite directions at this point, and this guy says something like "You're a dickhead, mate". That was weird. I walked by. These guys turned around, they harassed me and I just told them to "Go away please, I can't be bothered", or something like that, "I don't want to fight". I hate that, I hate violence. I go to walk away and hear another shout, and I just turn around and this guy hits me, quads [strikes with arm] me down. I was taken aback. They must have just seen that I looked different (Dan, 20).

A minority of participants had been subjected to extreme violence, although thankfully none of them was seriously hurt. Reports included being punched and kicked, being 'shouldered' and knocked to the floor, and being screamed at and spat on, through to someone getting 'stabbed in the face with a screwdriver'. One victim, lan, recalled an incident in which he and his friends had just got off the bus, on their way to a friend's house, when they were subject to verbal abuse from a stranger. As they tried to move away, the following incident occurred:

A big mob of them came out, for no reason, they all just attacked us ... One of our friends, who's fairly big, got his glasses knocked off so he couldn't see anything. He was knocked behind a bush and was being bottled and I couldn't see what was going on behind the bush, but I heard his voice. So I went to find out what was going on and there was two guys on him ... We [retreated inside and] were basically barricaded in this house. We called the police to say "Listen, they're actually still attacking us"; they were throwing bottles and rocks at this house, trying to break windows. It was completely unprovoked, we had done nothing to them (lan, 26).

While most of this violence took the form of unrelated 'one-off' events, some of it was part of a series of connected incidents that were perpetrated by the same people in one district of Leicester. A number of interviewees recalled these events occurring several years ago in the Saffron Lane part of the city, a mainly white area with higher than average levels of socio-economic disadvantage. They happened frequently over a period of several months, when participants were walking in groups across the public park on Saffron Lane. Suddenly they would find themselves confronted by a gang of youths who would greet them with verbal abuse ('greb', 'grunger') that rapidly escalated into physical violence. As Chris (22) states: 
There must have been about 20 people, some of them probably not even teenagers, but then you get the ones that were 17, 18, walking behind all the younger kids with golf clubs and everything. So the younger kids would all run at you, try and get you down and if you stayed down the older ones came and just attacked you with weapons.

Adrian's (21) experience was similarly terrifying:

We were walking down Saffron Lane, just before Aylestone Park ${ }^{6}$. I remember these two very young people, they were about 12 and what they would do, they would come and try and wind everyone up. They came and shouted. "What you grebs walking down here for?" and all that kind of stuff ... They then started to attack, they attacked my friend ... and then literally across Aylestone Park, these people with bikes and golf clubs came and we just ran ... They ended getting my friend in the face with a golf club ... they were just tearing at his clothes, beating him up ... That was a very frightening experience. We were shit scared of going down Saffron Lane again.

These attacks resulted in torn clothes, bruises and cuts, 'fat lips', black eyes and even a broken nose. That they occurred in a public space and in daylight is also troubling as it showed the fearlessness of the assailants and their confidence that there would be no comeback from their victims or the police. Equally of concern is the fact that these assaults occurred over a period of months and contained such high levels of violence. Whether there were others from backgrounds other than 'alternative' that were also attacked in this period is difficult to assess, but these events provide clear evidence that 'alternatives', like those from recognised hate crime victim groups, are the subjects of repeated, targeted harassment simply because of who they are. However, their relationship with their attackers (at least in this example) is arguably more complex than may at first appear, and this issue will be returned to later.

\section{Impact of Victimisation}

Around two-thirds of our interviewees described the impact of being a victim of targeted hostility in terms of its high significance. Common effects included feeling angry, upset, anxious, depressed, fearful and vulnerable, with these generally being heightened for victims of physical violence. Some participants spoke of the troubling impact of the 'drip drip' effect of constant harassment, with one 
suggesting that it 'chipped away' at her humanity because she was being targeted due to her identity (see Iganski (2008) for an outline of this process in other contexts). Another respondent mentioned how the nature of constant verbal abuse was 'really hateful. And people might think "Oh, it's just a comment", but if it's comment, comment, comment, then it hurts you' (Jane, 27). Being stared at was described by several participants as discomforting:

If it's out in the street as I'm moving it doesn't bother me that much, but when you are stood in the queue with your shopping and people behind you are just fixated, it makes you feel uncomfortable. It's a bit claustrophobic (Karen, 22).

Being the subject of physical assault understandably appeared to heighten the fear of further attack, causing victims to feel insecure and unsafe when out in public. A number of participants mentioned that being victimised had caused them to alter their behaviour, with one stating that he was now 'constantly looking over [his] shoulder' and had never returned to the place where he was attacked. Others stopped socialising, or if they did go out in the evening avoided certain parts of the city. Typical of similar comments were:

I didn't wanna go out at night anymore, walk alone, that kinda stuff. I was more aware that that could happen (Helen, 26).

If I can avoid walking down that street, l'll go the long way. It's just the groups of people that hang around there, it's just not worth the hassle ... It's usually at night really or in the evenings, you get people hanging around the centre and market stalls. It's just something you avoid if you can (Karen, 22).

As well as avoiding certain streets or places where they had previously been victimised, some interviewees also spurned public transport, preferring the security of taxis or cars. Others were wary of groups of males and would cross the street in order to reduce the chance of being victimised. However, around a third had fought back, either physically or verbally, when targeted. This approach could bring its own problems, as one interviewee revealed: 
I'm big myself so I shoulder him back, and then he went to punch me and I punched him back in retaliation, and as he kinda went back, suddenly all of them held me back and then his cousin ... came at me saying, "What you hit my cousin for?". Then he headbutted my nose, just to say "I'm better than you". And I did get the constant "You're nothing, you'll never amount to anything" speech from them as well (Ian, 26).

Although only a minority had felt the need to retaliate in this way, almost all of our participants expressed the determination that their own victimisation, however hurtful, would not deter them from continuing to lead their life in the way they had chosen. They felt strongly that they were not 'wearing anything offensive' (as one put it) and that being harassed due to their alternative 'look' only increased their desire to continue to be alternative, whatever the risks of attracting future opprobrium. Others noted how this process heightened their sense of group solidarity, but that this came at the risk of erecting boundaries between their 'in-group' and those outside of it. This could intensify feelings of antagonism towards the perpetrators of their victimisation (in their vocabulary, (chavs'), as one interviewee pointed out:

I think that's good in a way [developing communal bonds] but it also reinforces this sense of the other. It's good because it intensifies your community spirit, but it also solidifies your feeling against the other group. And I'm sure that that took place on both sides (Sarah, 27).

This sense of 'us and them', of inter-group rivalry and mutual antipathy, was a feature of many of the stories we heard from 'alternatives', and this issue will be returned to shortly. More positively, though, these accounts revealed the bonds of communal solidarity that many felt with one another, with attacks upon one impacting upon others, drawing them closer together. The resonance of the Sophie Lancaster case was also notable, with a number of interviewees mentioning how it had increased their awareness of the shared dangers that 'alternatives' face. Meanwhile, an older interviewee spoke of how her knowledge of the Lancaster case made her very concerned for the safety of her children, who also led alternative lifestyles.

\section{Making Sense of Being Targeted}

As mentioned above, most of our participants struggled to understand the motives behind their victimisation, often describing it as being 'senseless' or 'random'. Although incidents may often have 
seemed like this, in the sense that any alternative person could have been selected by the perpetrator, they appeared to have a motive behind them that was anything but 'senseless'. One of our participants recalled a particularly vicious assault in which he had been targeted simply because his attacker had taken exception to his alternative 'look' - his body art:

In 2009 I was stabbed opposite a police station on a main road. It took the police a few days to catch up with the person that did the offence and .... when they caught up with him, he explained to them that he just didn't like my appearance, the fact that I had pictures tattooed on my body (Alex, 38).

Several interviewees felt that they had been targeted simply 'for fun', as if there was no other reason behind their victimisation. Others, though, spoke of feeling like their difference made them 'stand out' as an obvious 'easy target'. Some suggested that their appearance caused others to perceive them as 'troubled' or 'unstable', or that they were rebelling against society's norms, which also generated anger. However, one of our participants, a male-to-female trans woman, knew exactly why she had been repeatedly targeted: it was her trans and goth identities that made her especially at risk of assault:

I know the level of harassment ... that I attract if you actually express your gender identity in ways that don't conform to perceived societal norms ... Because everyone has their own idea about what a trans person ought to look like as well, so if you actually combine that with a goth identity then you really are going to attract a lot of unwanted attention (Amanda, 48).

This issue of the intersection of different outgroup identities, which can create a 'fault line' that increases the risk of being targeted, has been noted elsewhere in the context of recognised hate crime victim groups (Chakraborti and Garland, 2015). In our sample, only a handful felt that another aspect of their identity (in each case their sexual orientation) was an additional factor in the aggression displayed towards them, although some males felt their androgynous appearance generated homophobic hostility. In many cases though, their explanation was far simpler: they were being persistently targeted by a certain social grouping who despised them. In the view of these participants, 'chavs' were responsible for perpetrating the violence they routinely experienced. 
While none ventured a detailed explanation as to what they meant by 'chav', the moniker appeared to be used in the context of describing young, white, working class males and females. It is a widely used term in the UK that is commonly understood to be an acronym of 'council housed and violent' (or something similar). It refers to the contemporary 'underclass' of poor, marginalised and disadvantaged white working class people, and is used in a similar context to that of the label 'bogan' in Australia (Pini, McDonald and Mayes, 2012). It is, though, a derogatory expression as it carries implications of fecklessness, aggression, vulgarity, fecundity, ignorance and poor taste (Skeggs, 2005; Raisborough, Frith and Klein, 2013). ${ }^{7}$

Indeed, 'chav' was used by participants in oppositional and disparaging terms, reinforcing the 'us and them' aspect of what one interviewee called the 'chav wars'. While some acknowledged that the term was 'quite nasty', making users 'no better' than their abusers, others felt using the label was merited:

But everybody calls chavs 'chavs', and I know it's equally as bad, but I don't know. I think they were kinda more horrible (Victoria, 32).

The use of 'chav' was not just restricted to the young people in our sample as older 'alternatives', such as Lucy (53), also felt they could use it with legitimate cause:

And yes, I am prejudiced against them because they're the people who spit at me and throw things at me and call me names... And even though their behaviour offends me, I just walk away and wouldn't do anything about it. Maybe they think that we think that we're better than them. And frankly, I think I am better.

The majority of our participants used the term 'chav' freely and without compunction, with some seemingly unfamiliar with its pejorative nature while others used it knowingly. Some openly acknowledged the prejudice that existed amongst 'alternatives':

[Because of] the prejudice and indiscriminate violence and stereotyping that the moshers would encounter themselves, they would stereotype people from the other group, the scallies, saying 
"They're all stupid, they're all drinking Lambrini from dusk until dawn", or "They're only doing this because they're too stupid to be able to read a book or anything"' (Kerry, 25).

A number of our participants acknowledged that this prejudice had resulted in a kind of 'vicious cycle' developing in relations between the two groups, with each regarding the other with increasing levels of disdain that fuelled the violence that followed. In the views of many, this enmity was along class lines (reflecting Pini et al.'s (2012) assertions, drawing on Bourdieu (1990), that class is relational, dynamic and a fusion of economic and cultural influences), with 'alternatives' seeing their 'enemy' as 'common', 'loud', 'thick' and 'vulgar', in contrast to their more middle-class, refined and educated selves. Although it is difficult to know just how strongly held these views were, or to what degree they influenced some to participate in acts of aggression, the fact that there was a two-sided conflict with antipathy on both sides - rather than purely a one-sided one with one group clearly the perpetrators and the other the victims - is a new insight into this phenomena. Some clearly felt that 'alternatives' were not the initiators of aggression but the recipients of 'chav' harassment and violence which they then, on occasion, reacted to, and much of the evidence gathered for this research seems to bear this out. Others were more vivid in their descriptions of this 'battle':

Even in school we were called 'grebs'. Even then it was us and them really, wasn't it? We were probably guilty ourselves of categorising people. It felt in our heads like it was a little war, it was the grebs and the chavs (Adrian, 21).

This group of chavs was literally waiting around for alternative people to come past, to attack them ... There was this real war of people between the chavs and the goths going on (Rachel, 24).

Others went further, describing acts that seemed to go beyond retaliation by resembling the kind of gang-related targeted violence described in Byers et al.'s study of the victimisation suffered by the Amish in the US (Byers, Cryder and Biggers, 1999), when groups of young men seeking thrills would search for an outgroup to bully and harass. As one of our participants recalled, there were occasions in his local area when 'alternatives' would be actively searching for their 'enemy' in order to abuse them: 
When I look back at it now, it was just as bad in a sense. I remember my friends going what they used to call 'chav hunting'. They used to go in a car and throw stuff at people who dressed like chavs. That was retaliation (Mike, 23).

This desire for revenge, which stemmed from anger at being targeted in the first place, showed that many 'alternatives' rejected the idea that they were 'passive victims' of harassment. Indeed, this anger appeared to fuel feelings amongst some 'alternatives' that went beyond merely disliking 'chavs': in some cases, they 'hated' them, and felt they had every reason to do so:

Well, we hated them. We wouldn't have beaten them up, but we would have fucking taken the piss out of them ... It was justified hate. It was, it was justified (Andrea, 25).

\section{Violence against 'Alternatives': Towards a Better Understanding}

As we have seen above, the 'alternatives' in our study were routinely victims of targeted hostility from members of the public. Most commonly, they were verbally abused, with 'grunger' or 'greb' commonly-used pejorative terms for anyone of an alternative appearance, with their implications of being unkempt and dirty. Interestingly, many of our participants recalled being told that they were 'worthless' and would never amount to anything. By being outside of the mainstream, 'alternatives' implicitly challenge the 'accepted' way of role performance in a number of ways and, as some of our participants suggested, this may provoke feelings of hostility in those who cherish and wish to safeguard conventional or more traditional lifestyles.

Others recalled being frequently stared at as though they were some alien 'other', and it may be that a fear of difference was behind much of this apparent aggression. It could be that, by dressing in an androgynous or 'provocative' fashion, 'alternatives' were inadvertently questioning gender norms and accepted ways that men and women should look and behave. This heightened their risk of being abused and harassed, especially if they were in situations - isolated on public transport or on the street late at night in town centres - that made them appear especially vulnerable to those whose latent prejudice is prone to come to the surface in such circumstances (Walters, 2011; Chakraborti and Garland, 2012). This could explain some of the homophobic abuse directed at heterosexual male goths of feminine appearance in both our and Brill's (2008) studies, and may highlight the increased risk of violence faced by those whose appearance not only generates anxiety in itself, but also the suspicion that they are not performing their gender roles 'properly'. 
However, while our findings indicate that the nature and impact of the targeted hostility suffered by those from alternative subcultures may resemble that of the recognised hate crime victim groups, it may be that class also plays an important role in the victimisation of 'alternatives', and especially those, like goths, who are generally middle-class and university educated (Hodkinson, 2002). Indeed, some of our interviewees felt that they were targeted because of their class background, and that this was driven by jealousy and bitterness on the part of 'chavs' at the alternatives' relatively successful social position, and by anger fuelled by a perception that they were somehow being 'judged' and looked down upon (see Skeggs and Loveday, 2012). However, interwoven with this association of 'alternatives' with relative wealth and being 'highbrow' are other stereotypes, such as bookishness, shyness and passiveness, which some may correlate with a lack of physical strength. As Chakraborti and Garland (2012) note, this can exacerbate the suggestion that 'alternatives' are a 'soft touch', vulnerable to bullying and intimidation as their attacker feels confident that they will not be challenged. Crucially though, and in line with Leblanc's (2008) study of the reaction of punks when harassed, a minority of our participants did retaliate against their assailants, including using physical force. Sometimes, as was illustrated above, this was out of perceived necessity, but at other times it was driven by the desire not to be labelled as a victim, with its negative connotations of weakness and helplessness. Thus it may be the case that the 'victim group' in this instance is aware of the dangers of being perceived as an 'easy target', and is seeking to counter this idea.

Moreover, the experience of suffering targeted hostility brings the alternative community closer together, strengthening feelings of internal solidarity. Accompanying this process though was the drawing of exclusionary boundaries between that group and outsiders, and especially between members and those victimising them: the 'chavs'. As a number of participants acknowledged, many within the alternative community hold negative views of 'chavs', stereotyping them as uneducated, ignorant and workshy. Inherent within this process was not just the invocation of a demonised 'other' but also the tightening of internal bonds within the alternative community through the 'collective reassurance that we are not alone in our judgement of the disgusting object, generating consensus and authorization for middle-class standards, maintaining the symbolic order' (Skeggs, 2005: 970). Others, though, saw 'chavs' as the despised enemy with whom they were literally 'at war', and for some within the alternative community this dislike bordered upon legitimate hatred. In some cases at least, then, the circumstances surrounding the targeted hostility suffered by 'alternatives' reveals a more complex, 'two-sided' conflict in which the victim-perpetrator duality is blurred, creating challenges for hate crime theoreticians and suggesting that further empirical work is needed in this field in order to untangle these complexities. 


\section{Conclusions: Acknowledging the 'Little War'}

This article set out to examine a hitherto under-explored area within the wider field of victimology and the narrower study of hate crime: the targeted hostility suffered by those from alternative subcultures. The findings from our research indicate that violence against 'alternatives' is a significant issue in terms of its nature, frequency and impact. For many of our participants, the experience of being targeted was distressing, and had consequences which affected the victim's mental and physical wellbeing. It could also damage their sense of self-worth and security as it was a core part of their identity - their 'alternativeness' - that was being targeted, revealing similarities between the impact of this type of victimisation and that experienced by recognised hate crime victim groups.

A crucial, and thus-far hidden feature of this hostility, is that it may form part of a cycle of violence that occurs between those in the alternative community and their 'foe', the 'chavs'. Indeed, some of our interviewees admitted that the situation between the two groups had at times resembled a 'little war', with both 'sides' developing an entrenched, negative opinion of the other steeped in relational class formulations that reinforce a sense of grievance on the one hand, and a sense of internal group solidarity on the other. For some 'alternatives' this was informed by what they (somewhat shamefully) acknowledged as prejudice against a group they instinctively loathed, while for others this hatred was 'justified' as it was directed against those who regularly bullied, insulted and attacked them. Yet, while the language employed regarding so-called 'chavs' was often emotive, it should be remembered that none of our interviewees felt that 'alternatives' committed unprovoked attacks against their 'enemy'. Instead, any acts of aggression from 'alternatives' were those borne out of a desire to retaliate which, while still morally dubious, was nevertheless in many ways understandable. Therefore, while at times it appeared on the surface that the enmity between the two groups resembled an ongoing conflict, in reality one group was, almost always, the subject of unprovoked aggression from the other. This key aspect of the 'little war' needs to be recognised if alternative communities are to be afforded the protection from targeted violence that they have every right to receive.

Funding The authors were in receipt of an ESRC Grant (ESRC/ES/J008109/1) which funded the research upon which this article is based. 


\section{References}

Becker H (1963) Outsiders: Studies in the Sociology of Deviance. New York: Free Press.

Bourdieu P (1990) In Other Words: Essays Towards a Reflexive Sociology. Stanford, CA: Stanford University Press.

Brill D (2008) Goth Culture: Gender, Sexuality and Style. Oxford: Berg.

Brown A (2011) Suicide solutions: or, how the emo class of 2008 were able to contest their media demonization, whereas the headbangers, burnouts or 'children of ZoSo' generation were not. Popular Music History. 6.1/6.2: 19-37.

Byers B, Crider BW and Biggers GK (1999) Bias crime motivation: a study of hate crime offender neutralization techniques used against the Amish. Journal of Contemporary Criminal Justice, 15(1): 78-96.

Chakraborti N and Garland J (2012) Reconceptualising hate crime victimisation through the lens of vulnerability and 'difference'. Theoretical Criminology 16(4): 499-514.

Chakraborti, N and Garland J (2015) Hate Crime: Impacts, Causes and Responses (2 ${ }^{\text {nd }}$ edition). London: Sage.

Cohen A (1955) Delinquent Boys: The Culture of the Gang. London: Collier-MacMillan.

Cohen P (1972) Subcultural conflict and working class community. Working Papers in Cultural Studies, 2: 5-70.

Cohen S (1972) Folk Devils and Moral Panics: The Creation of Mods and Rockers. London: Granada.

Fowler D (2008) Youth Culture in Modern Britain, c. 1920-c. 1970, Basingstoke: Palgrave Macmillan.

Gaines D (1990) Teenage Wasteland: Suburbia's Dead-End Kids, Chicago: University of Chicago Press.

Garland J (2010) 'It's a mosher just been banged for no reason': assessing the victimisation of goths and the boundaries of hate crime. International Review of Victimology. 17(2): 159-177.

Garland, J. and Hodkinson, P. (2014) Alternative subcultures and hate crime. In N. Hall, A. Corb, P. Giannasi and J. Grieve (eds) The International Handbook of Hate Crime, London: Routledge, pp. 226-236.

Goulding C and Saren M (2009) Performing identity: an analysis of gender expressions at the Whitby goth festival. Consumption Markets \& Culture. 12(1): 27-46.

Greater Manchester Police (GMP) (2013) 'Hate Crime' at http://www.gmp.police.uk/content/section.html?readform\&s=C4D5E39C4F3817F68025796100 4019B9, accessed 2 February 2015.

HM Government (2012) Challenge It, Report It, Stop It: the Government's Plan to Tackle Hate Crime, London: HM Government.

Hebdige D (1979) Subculture: The Meaning of Style. London: Routledge. 
Hodkinson P (2013) Family and parenthood in an ageing 'youth' culture: a collective embrace of dominant adulthood? Sociology. 47(6): 1072-1087.

Hodkinson P (2002) Goth: Identity, Style and Subculture. Oxford: Berg.

Iganski P (2008) Hate Crime and the City. Bristol: The Policy Press.

Jefferson T (1976) Cultural responses of the Teds: the defence of space and status. In: Hall S and Jefferson T (eds), Resistance Through Rituals: Youth Cultures in Post-War Britain, London: Hutchinson.

Leblanc L (2008) Pretty in Punk: Girls' Gender Resistance in a Boys' Subculture. New Brunswick, US: Rutgers University Press.

Perry B (2001) In the Name of Hate: Understanding Hate Crimes. London: Routledge.

Pini B, McDonald P and Mayes R (2012) Class contestations and Australia's resource boom: the emergence of the 'cashed-up bogan'. Sociology. 46(1): 142-158.

Raisborough J, Frith $\mathrm{H}$ and Klein $\mathrm{O}$ (2013) Media and class-making: What lessons are learnt when a celebrity chav dies? Sociology. 47(2): 251-266.

Skeggs B (2005) The making of class and gender through visualizing moral subject formation. Sociology. 39(5): 965-982.

Skeggs B and Loveday V (2012) Struggles for value: value practices, injustice, judgment, affect and the idea of class. The British Journal of Sociology. 63(3): 472-490.

Thornton S (1995) Club Cultures: Music, Media and Subcultural Capital, Cambridge: Polity.

Walters MA (2011) A general theories of hate crime? Strain, doing difference and self control. Critical Criminology. 19(4): 313-330.

Jon Garland is a Reader in Criminology at the University of Surrey. His research specialisms are in the fields of hate crime, community, identity and vulnerability, rural racism, racism and antiracism in football, and policing. Neil Chakraborti is a Professor of Criminology at the University of Leicester. He has researched and published extensively in the field of hate crime, with a particular focus on issues of targeted violence, victimisation and 'difference'.

Stevie-Jade Hardy is a Lecturer in Hate Studies at the University of Leicester. Her research has largely focused on everyday multiculturalism, 'difference' and targeted hostility, and she has published on hate crime perpetration and victimisation. 
1 The Foundation was instigated by Sylvia Lancaster following the murder of her daughter, Sophie, who was targeted by her attackers due to their aversion to her 'gothic', alternative appearance (Chakraborti and Garland, 2015).

2 The findings from the ESRC-funded Leicester Hate Crime Project are available at http://www2.le.ac.uk/departments/criminology/research/current-projects/hate-crime/our-reports-1.

3 Over the course of the fieldwork the project team engaged with in excess of 4,000 members of established and emerging minority communities in Leicester. A total of 1,106 questionnaires were completed by victims of hate crime: 808 on paper and 298 online. In addition, a total of 374 victims were interviewed, with 62 defining themselves as being from an alternative subcultural background.

454 of the 1,106 survey respondents stated that they had been targeted due to their alternative subcultural appearance. Of these, nine also took part in interviews, with the rest of our sample of 62 subcultural participant interviewees being recruited via the snowballing process described within the main body of the article. Braunstone is an area of Leicester located in the west of the city.

6 Saffron Lane and Aylestone Park are in the south of the city.

7 'Scally' is another widely-used term with similar connotations. 